\title{
RESENHAS
}

\section{POLÍTICAS ATUAIS PARA O ENSINO MÉDIO}

Maria Sylvia Simões Bueno

São Paulo: Papirus, Fapesp, 2000, 255p.

Em um texto de conteúdo denso e rigorosamente fundamentado, em estilo contundente, ágil e literariamente envolvente, a autora, seguindo o exemplo de Sousa Santos, toma decididamente "a mão de Alice" e entra no mundo espelhado do discurso político-educacional hegemônico e das decisões oficiais, para desvendar suas origens, contradições e seus desdobramentos. O resultado dessa incursão é uma crítica muito esclarecedora a respeito das novas políticas para o ensino médio. A crítica, no entanto, não se esgota em si, mas abre espaços para que se visualizem alternativas políticas mais democráticas e produtivas.

É preciso notar que a abrangência da análise e as soluções sugeridas desvelam não somente a solidez da formação teórica de Maria Sylvia Simões Bueno mas também sua sensibilidade em relação à prática educacional do cotidiano escolar, sensibilidade desenvolvida durante os muitos anos em que trabalhou como professora e como técnica na rede pública de ensino médio do Estado de São Paulo.

O livro é estimulante em diversos sentidos. Em um primeiro nível, pode ser considerado fonte exaustiva de referências documentais sobre as políticas educacionais da última década. De fato, o emaranhado de relatórios, pareceres, avaliações, sugestões e acordos - originados em agências internacionais, como o Banco Mundial e o Banco Interamericano do Desenvolvimento - é deslindado e referido no contexto mais amplo da construção das políticas nacionais. Documentos, relatórios e textos de diversas modalidades - emitidos pelo Ministério da Educação, pelo Ministério do Trabalho, pelo Conselho Nacional de Educação e por outros órgãos governamentais - são cui- dadosamente analisados ao longo da discussão do tema. Diferentes aspectos dos mais importantes instrumentos da legislação atual são examinados em sua gênese e em suas conseqüências. Assim, em uma primeira aproximação, o texto em pauta já pode ser considerado contribuição inestimável de registro e análise de documentos de política educacional.

Em um segundo nível, a articulação das análises documentais, apoiadas em ampla e atualizada bibliografia teórico-analítica, constrói um painel multifacetado, muito bem encadeado, no tempo e no espaço, o qual, desvendando paulatinamente ao leitor as ambigüidades dos discursos políticos, as tortuosas entrelinhas dos documentos legais e as contradições das práticas administrativas e das orientações pedagógicas, permite uma visão crítica do conjunto das políticas para o ensino médio e de seus possíveis desdobramentos.

Extremamente didático, o livro põe em destaque o caminho metodológico seguido, esclarecendo que a proposta é um "mergulho no processo de construção discursiva com o objetivo de explicitar como texto e contexto interagem, isto é, em que contexto se constroem os textos e como alguns textos constroem categorias de pensamento que passam a influenciar os contextos" (p. 26).

Entretanto, a preocupação científico-didático-ética vai mais longe. Ou seja, nadando contra a corrente, a autora faz questão de explicitar sua adesão a referenciais explicativos marxistas ou marxianos. Nesse campo, aponta que, para muitos estudiosos, tornou-se "um verdadeiro drama hamletiano" a adesão a uma perspectiva de análise que foge dos atuais padrões analíticos consensuais, padrões que anulam diferenças, sintetizam "positividades" e condenam confrontações - sempre desqualificadas como "jurássicas" -, "produzindo uma espécie de centro de atração político-intelectual alargado que condiciona o 'ser'”. Fora do panparadigma emergente, "parece haver uma 
inexorável condenação ao 'não ser'”(p. 2I). Desafiando essa condição e apoiando-se em estudiosos como Bobbio e Perry Anderson, a autora rejeita a tese segundo a qual está superada a polarização direita e esquerda. De sua perspectiva de esquerda, porém, adverte que a crítica necessária deve vir acompanhada de propostas elaboradas no interior da "nova ordem", propostas que só terão repercussão significativa se "fundamentadas em pesquisas consistentes e traduzirem formas de interferência dinâmica e positiva na realidade educacional" (p. 26).

Parece oportuno enfatizar que a clara opção teórico-metodológica política da autora é particularmente notável em um tempo em que o referencial marxista, mesmo quando considerado indispensável para a compreensão da realidade, tornou-se, para muitos pesquisadores, o paradigma "que não ousa dizer seu nome", cuidadosamente ocultado com a argumentação pouco rigorosa de que "os referenciais não precisam ser explicitados, pois, quando usados corretamente, podem ser inferidos pelo leitor", afirmação que contraria o princípio científico básico da transparência e da difusão clara e objetiva do processo de construção do conhecimento.

A dimensão histórica, irrecusável na abordagem escolhida, apresenta-se com várias facetas ao longo do texto, sendo uma das mais estimulantes aquela que, em tom levemente irônico e metafórico, compara o processo de instalação das colônias ibéricas na América Latina ao atual modelo de relações internacionais, bem exemplificado pela submissão de nossas políticas educacionais a consensos artificialmente forjados em nível internacional.

A autora deixa claro que as profundas e rápidas transformações nas relações econômicas internacionais, na ciência, na tecnologia, na organização da produção de bens e serviços e nas formas de circulação da informação não podem ser ignoradas. No entanto, julga um grave equívoco adotar uma interpretação linear de todos esses processos, interpretação transformada pelos policy makers em pressupostos pétreos, os quais, pas- sando ao largo de todas as incertezas e contradições da atualidade, são usados como fundamentos de políticas uniformes destinadas a países e regiões muito diferentes.

Entre as perigosas simplificações e contradições conceituais e políticas que orientam as novas diretrizes educacionais, a autora destaca as seguintes: a suprema responsabilidade pelas transformações sociais atribuída à educação, ao mesmo tempo em que ela é reduzida a fator que contribui para associar crescimento econômico, qualidade de vida e democratização; o rebaixamento do conhecimento humano a recurso estratégico do desenvolvimento, confundido com informação e, nessa dimensão, considerado como base de cidadania política; a concepção redutora de trabalho, visto como mero fator de produção; a visão messiânica da tecnologia, plantada num contexto em que a relação linear entre desenvolvimento humano e mercado potencial constitui um paradoxo; a concepção de necessidades humanas que tem por referência a finitude da economia e não o homem em sua plenitude; o raciocínio economicista/empresarial, subjacente aos modelos educacionais e de financiamento, que associa uma ênfase na qualidade de ações centradas em objetivos quantitativos; o conceito de qualidade vinculado à perspectiva empresarial de eficiência, eficácia e política de resultados e identificado com aperfeiçoamento de capital humano pela otimização dos meios; a visão difusa de educação tecnológica associada a uma divisão inexorável entre escolas de formação geral e ensino profissionalizante (p. 120). Nesse quadro, fica evidente o paradoxo representado pela importância conferida, pelo discurso oficial, ao ensino médio e a perspectiva governamental de manter uma política de enxugamento de investimentos e redistribuição financeira na área educacional.

Todas essas e outras contradições e elaborações ideológicas são minuciosamente discutidas pela autora e analisados seus desdobramentos no âmbito de decisões políticas efetivamente implementadas. Adicionalmente, o próprio processo de construção das diversas diretrizes governamentais 
é examinado em detalhe, pondo a nu o substrato pouco democrático dos procedimentos adotados.

No prefácio, Celestino Alves da Silva Jr. resume bem a contribuição do livro de Maria Sylvia: "confrontar a escuridão, trazer luz ao debate e trazer à luz as forças em debate." Em tempos de prevalência de "pensamento único", que melhor qualificação para um trabalho científico?

Dagmar Zibas

Fundação Carlos Chagas

\section{O CENÁRIO EDUCACIONAL LATINO- AMERICANO NO LIMIAR DO SÉCULO XXI: REFORMAS EM DEBATE}

Nora Krawczyk, Maria Malta Campos e Sérgio Haddad (orgs.)

Campinas: Autores Associados, 2000, I 40 p.

A coletânea reúne textos preparados para o ciclo de debates A construção social das políticas educacionais no Brasil e na América Latina, realizado em 1999 pela Pontifícia Universidade Católica de São Paulo, em que os autores abordam os nexos entre as reformas educativas em curso neste final de século e as mudanças socioculturais e políticas associadas à globalização econômica, à preeminência das orientações neoliberais nos processos de reforma do Estado e de ajuste econômico implementados nos países do continente, bem como a influência de organismos e bancos internacionais sobre esses eventos.

"A incomparável virtude do mercado: políticas sociais e padrões de atuação do Estado nos marcos do neoliberalismo" é o título do artigo em que o filósofo Reginaldo Carmello Corrêa de Moraes analisa argumentos com os quais determinadas correntes do pensamento neoliberal prescrevem a mudança do papel do Estado na gestão das políticas sociais e na provisão dos serviços educacionais. O professor da Universidade Estadual de Campinas procura demonstrar que a doutrina neoliberal recupera antigas teses do liberalismo clássico sobre as supostas vantagens do mercado em relação ao Estado como instância reguladora da vida social, com base nas quais tenta sustentar prescrições conservadoras sobre a necessidade de colocar limites ao campo da governabilidade democrática mediante a restrição dos âmbitos de incidência do voto popular.

O autor historia a evolução do pensamento neoliberal na segunda metade do século $X X$ e sumariza suas três vertentes principais: a escola austríaca, liderada por Friedrich von Hayek; a escola de Chicago, conhecida pela obra de Milton Friedman e pela teoria do capital humano de T.W. Schultz; e a escola de Virgínia, cujo expoente é o economista norte-americano James M. Buchanan. Moraes elege esta última corrente para uma análise crítica mais aprofundada dos pressupostos e argumentos elaborados pela chamada teoria da Public Choice.

No intento de transportar a lógica operativa do mercado aos bens públicos, as doutrinas neoliberais propõem que as políticas sociais compensatórias de alívio da pobreza sejam orientadas pelas diretrizes de focalização, descentralização e privatização. Quando as políticas têm por objeto serviços sociais públicos cuja oferta em nível básico deva ser universal, como é o caso da educação, essas teorias propõem que se busque conciliar provisão pública e produção privada, modelo que pode contemplar ainda a participação do chamado terceiro setor. Na interpretação de Moraes, a ênfase depositada nos processos de reforma educacional em curso na América Latina e no Brasil para os sistemas de avaliação das políticas públicas tem por finalidade simular mecanismos mercantis, como a lógica fornecedor-cliente.

Em "Espaço público e educação" o professor da Pontifícia Universidade Católica de São Paulo Luiz Eduardo Wanderley volta ao tema da esfera pública democrática para abordar a construção social das políticas educacionais no Brasil. Apoiado em Jürgen Habermas e Norberto Bobbio, o autor salienta a historicidade do conceito de espaço público, construído no jogo de distanciamento e interpenetração das esferas pública e privada ao longo da modernidade. $\bigcirc$ enunciado de um con- 